\title{
¿Cómo se relacionan los jóvenes con los saberes artísticos dentro y fuera de la escuela? Un estudio de caso
}

How do young people relate to artistic knowledge inside and outside school? A case study

Como os jovens se relacionam com o conhecimento artístico dentro e fora da escola? Um estudo de caso

María Reyes González Vida ${ }^{1}$

Idoia Marcellán Baraze ${ }^{2}$

Amaia Arriaga ${ }^{3}$

${ }^{1}$ Universidad de Granada, Granada, España, mrgv@ugr.es

${ }^{2}$ Universidad del País Vasco, Bizkaia, España, idoia.marcellan@ehu.eus

3 Universidad Pública de Navarra, Navarra, España, amaia.arriaga@unavarra.es

\section{Resumen}

En este artículo se presenta el estudio de caso de cómo dos jóvenes ponen en juego una serie de saberes artísticos para producir cultura visual dentro y fuera de la escuela. Este análisis se contrasta y amplía con los resultados extraídos de un cuestionario pasado a 786 jóvenes españoles de 14 a 18 años que indaga sobre su actividad como productores de cultura visual en ambos entornos. Entre las conclusiones destaca el hecho de que los saberes no puramente escolares tienen gran importancia en las producciones visuales de los jóvenes y se subraya el valor formativo de los espacios no escolares para estos jóvenes.

Palabras clave: Jóvenes. Producción. Cultura visual.

\begin{abstract}
The article presents a case study on how two young people put into play artistic knowledge to produce visual culture inside and outside the school. This analysis is contrasted and extended with the results extracted from a questionnaire answered in Spain by 786 young people aged 14-18. The questionnaire inquired about their activity as producers of culture in both environments. The first conclusions indicate
\end{abstract}


that non school knowledge is of great importance in the visual productions of young people and highlight the educational value of non-school spaces for these young people.

Keywords: Youth. Production. Visual culture.

\section{Resumo}

Neste artigo apresenta-se um estudo de caso de como dois jovens que colocaram em prática conhecimentos artísticos para produzir cultura visual, dentro e fora da escola. Esta análise é contrastada e ampliada com os resultados extraídos de um questionário passado a 786 jovens entre os 14 e os 18 anos, em Espanha, que os indagou sobre a sua actividade como produtores de cultura visual em ambos os ambientes. Entre as primeiras conclusões, destaca-se que os saberes não puramente escolares têm grande importância nas produções visuais dos jovens e o valor formativo que têm os espaços não-escolares para esses jovens.

Palavras-chave: Jovens. Produção. Cultura visual.

\section{Introducción}

El artículo presentado se enmarca en el proyecto de investigación titulado "Jóvenes productores de cultura visual: Competencias y saberes artísticos en educación secundaria" (EDU 2009-13712), financiado por el Ministerio de Ciencia e Innovación del gobierno de España. Propone detectar cómo los jóvenes españoles se relacionan con los saberes dentro y fuera de la escuela para producir cultura visual. Se parte de la hipótesis de que existe un gran distanciamiento entre estos dos entornos de aprendizaje, y con la investigación se pretende favorecer un acercamiento entre los saberes artísticos propuestos desde la escuela y los que, cotidianamente, los jóvenes manejan y adquieren fuera de la misma.

Tradicionalmente, los enfoques de investigación han dirigido su mirada a explorar el consumo de los productos audiovisuales por parte de los jóvenes, lo que venía motivado por la creciente preocupación de la capacidad de influencia de la cultura visual, especialmente la de tipo mediático, en sus vidas (MARCELLÁN y AGIRRE, 2008). Sin embargo, en los últimos años, se han puesto en marcha varios proyectos 
de investigación que ponen el foco en la faceta productiva de los jóvenes respecto a la cultura visual. Los primeros se centraron en el análisis de las producciones de cultura visual de varias subculturas, como el estudio de Karpati y Kovacs (1997) sobre los adolescentes húngaros. Otros estudios han puesto el foco en la producción visual de jóvenes que son fans de narrativas culturales populares (cultura fan) (MANIFOLD, 2009) o han examinado las experiencias de aprendizaje que los jóvenes tienen en grupos informales de cultura visual ("informal art groups"), como el de Kerry Freedman, Heijnen, Kallio-Tavin, Kárpáti y Papp (2013).

De la misma forma, cada vez más, se están desarrollando estudios que se circunscriben a prácticas de producción visual relacionadas con la utilización de nuevas tecnologías por parte de los jóvenes (ITO, BAUMER, BITTANTI, BOYD, CODY, HERR-STEPHENSON, et al., 2008) y especialmente con la producción online (LEANDER y FRANK, 2006; STERN, 1999), explorando la forma en que los nuevos medios han cambiado las relaciones, las identidades y las comunidades de los adolescentes y las implicaciones que este cambio supone en el desarrollo de sus saberes y sus aprendizajes.

El trabajo aquí presentado se sitúa en el marco establecido por estas recientes líneas de investigación, que ponen el foco en la exploración de la faceta productiva de los jóvenes y bebe especialmente de los estudios que indagan sobre cómo y dónde adquieren los jóvenes sus competencias y saberes, comparando entornos formales e informales de aprendizaje (FREEDMAN et al. 2013; ITO et al., 2008).

Bajo este marco, el artículo presenta un estudio de caso que analiza la forma en que dos jóvenes ponen en juego una serie de saberes para producir cultura visual fuera de la escuela. Explora, para ello, las lógicas de producción que actúan en su contexto de creación, examinando los conocimientos que manejan, sus rituales de selección y apropiación, así como las técnicas y las estrategias que utilizan para llevar a cabo sus producciones.

Las reflexiones sobre los conocimientos y prácticas que estos jóvenes ponen en juego fuera de la escuela, se contrastan con los saberes que reconocen como propiamente escolares, y que vinculan con las clases de Educación Plástica y Visual. Igualmente, se contrastan con resultados extraídos de un cuestionario pasado a 786 chicos y chicas de $4^{\mathrm{o}}$ curso de la Enseñanza Secundaria Obligatoria y $1^{\circ}$ de Bachillerato de varios centros educativos españoles que indaga sobre su actividad como productores de cultura visual. 


\section{Metodología}

Para el desarrollo del proyecto se han combinado métodos e instrumentos de investigación cualitativa y cuantitativa que permiten obtener indicios sobre cómo los jóvenes interactúan con los saberes artísticos y estéticos que obtienen tanto dentro de las clases como fuera de ellas y cómo repercuten en sus producciones. En un primer momento, se pasó un cuestionario a 786 chicos y chicas de $4^{\circ}$ curso de la Enseñanza Secundaria Obligatoria y $1^{\circ}$ de Bachillerato de varios centros españoles. A través de las respuestas obtenidas se estableció un mapa que ayudaba a determinar qué producen y las circunstancias en las que discurre la actividad productora, qué piensan que necesitan para aprender mejor, qué les interesa de lo que hacen en clase y si utilizan o no sus ideas en las actividades planteadas en Educación Plástica y Visual.

Seguidamente, para obtener matices al respecto, se realizaron diez entrevistas en profundidad en las que los jóvenes entrevistados en diferentes puntos del Estado español comentaron y ampliaron respuestas dadas en el cuestionario y presentaron narraciones de situaciones como productores de cultura visual, exponiendo acontecimientos que consideraban relevantes de su vida en este sentido. La voluntad de colaboración (que suele ser frágil en este sector de la población) fue el principal criterio para la selección de esta muestra.

En este artículo se examina y visibiliza lo aportado por dos de los entrevistados acerca de sus experiencias en clase de Educación Visual y Plástica y fuera de ella: Pabloun chico de 14 años- y Ana -de 16 años- de $4^{\circ}$ de la Educación Secundaria Obligatoria y $1^{\mathrm{o}}$ de Bachillerato respectivamente, ambos de Granada (España). Se realiza un estudio de caso de estos dos jóvenes, en concreto, por la gran cantidad de producciones que, a diferencia del resto de los entrevistados, nos han aportado, desarrolladas tanto en clase como fuera de ella, permitiéndonos incluso el acceso a su hogar y a sus lugares de creación. Esta situación nos permite realizar no sólo un análisis de discurso centrado en las opiniones que muestran en sus entrevistas, sino una lectura de los aspectos icónicos e iconográficos de las imágenes que producen, detectando los saberes con los que se vinculan. Además, como veremos más adelante, ambos producen una cultura visual que, en principio, dista bastante de lo que habitualmente se atribuye a la juventud, por lo que estos casos suponen un ejemplo muy evidente de la gran diversidad productiva que los jóvenes del siglo XXI llevan a cabo. 
El estudio de sus relatos se contrasta y amplía en este artículo, además, con resultados extraídos del análisis de los cuestionarios pasados a los jóvenes de distintos centros educativos españoles.

El presente texto se articula en torno a tres problemas eje de la investigación general, cuyos resultados mostramos en el siguiente apartado:

1. Sobre los saberes no puramente escolares que ponen en juego para realizar sus producciones visuales.

2. Sobre el valor formativo que otorgan a los saberes no escolares.

3. Sobre la repercusión del saber escolar en la construcción de los jóvenes como productores de cultura visual.

\section{Resultados}

\subsection{Sobre los saberes no escolares que ponen en juego para realizar sus producciones visuales}

De los relatos de Pablo y Ana se desprende que para realizar sus producciones visuales ponen en juego una serie de saberes que han sido adquiridos fuera de la escuela, principalmente en el entorno familiar: Ana hace manualidades con su madre, que es una apasionada del punto de cruz y de las manualidades en general, y Pablo, en sus momentos de ocio, hace dibujos inspirados en la Semana Santa, interés que sitúa como consecuencia de haber crecido en un ambiente familiar religioso en el que, además, tiene familiares artistas “(...) hay escultores, hay alfareros, hay también pintores...”, algunos vinculados a la imaginería religiosa.

El entorno familiar parece tener una influencia significativa en las producciones que los jóvenes hacen fuera del aula. No obstante, hay que entender la importancia de este dato con cuidado, ya que tanto Ana como Pablo son personas que tienen una visión muy interesada y cómplice con las actividades creativas y, por ello, sus casos no constituyen datos generalizables. De hecho, este dato no se vio reflejado en las respuestas que los 786 jóvenes dieron al cuestionario, ya que sólo un 14\% situó en el entorno familiar su entrada en el mundo de la producción de imágenes. La mayor parte de estos jóvenes señalaron que su aprendizaje se había producido de manera autodidacta (AGUIRRE, I., ARRIAGA, A., GONZÁLEZ, M.R., MARCELLÁN, I., CALVELHE, L. y OLÁIZ, I., 2015). 


\subsubsection{Saberes técnicos y artesanales}

Tanto en el caso de Ana como en el de Pablo hemos detectado el manejo de determinados saberes de tipo técnico, que focalizan en el conocimiento de técnicas y en el manejo de materiales e instrumentos específicos de los ámbitos en los que se desarrollan.

Ana está interesada por las manualidades y la artesanía, y sabe, por ejemplo, interpretar las guías de punto de cruz. Los símbolos de estas guías le ayudan a interpretar las luces, las sombras y los distintos colores en los patrones, a partir de los que hace sus dibujos a carboncillo o a acuarela. Utiliza estas guías como una referencia que le ayuda a estudiar el clarosuro en las imágenes.

Tiene también un especial gusto por las miniaturas: colecciona llaveros artesanales pequeños y le gusta hacer su propia bisutería. Para fabricarlos investiga sobre materiales y técnicas, poniendo en juego saberes que encuentra fuera de la escuela.

Ana (A): iSí! iMe gustan mucho las cosas chiquitinas...! iTengo un montón de cosas chiquitas!iY esto...! (enseñando un llavero de duende y otro de bruja)... Estoy buscando la fórmula, a ver cómo demonios se hace esta pasta!

Ana también diseña camisetas y el manejo del material ocupa un papel importante para ella: usa rotuladores con purpurina, con pintura "que se infla", glitters, lentejuelas, etc. Conoce cada material y sus diseños están condicionados por la naturaleza de estos materiales (Figura 1).

Como vemos, Ana posee un conocimiento muy experto en lo que a manualidades se refiere. Maneja un vocabulario muy amplio sobre materiales y conoce e investiga técnicas que comparte con su madre, fuera del colegio. Es interesante observar cómo estos saberes aparecen frecuentemente asociados a estéticas vinculadas con la industria mediática, como la de los dibujos animados observada en las camisetas de Ana. De manera similar, su gusto por determinados materiales y técnicas marca la estética de sus producciones.

Por su parte, Pablo hace dibujos inspirados en la Semana Santa desde que tenía 4 años. Sabe utilizar el grafito, el carboncillo y la sanguina para encajar y sombrear estos dibujos, conocimientos que reconoce haber adquirido fuera del aula utilizando el juego Art Academy de Nintendo, y bajo influencia de su tío, artista, que opina sobre sus dibujos. 
Figura 1

Camisetas diseñadas por Ana.
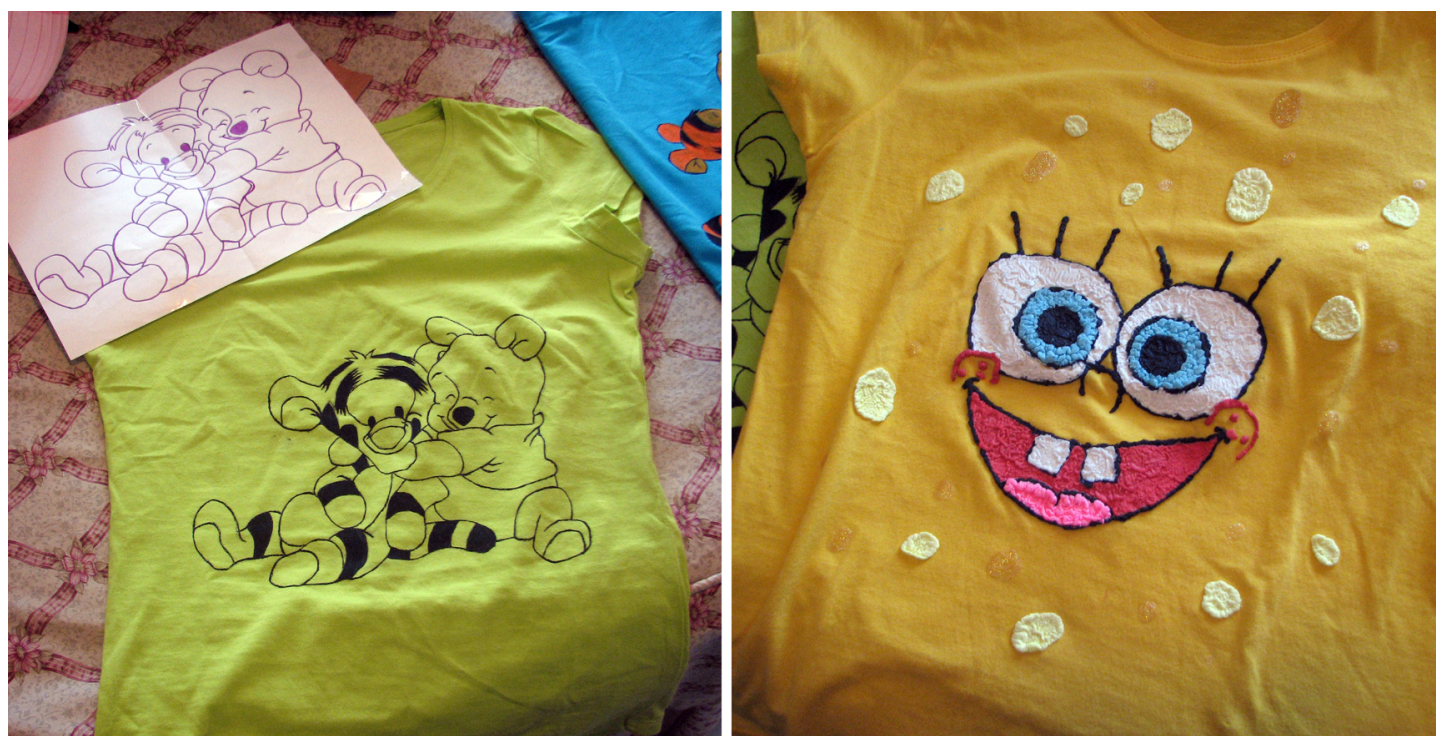

Fuente: propia.

Pablo ha adquirido también fuera del aula saberes técnicos que le ayudan a manejar su cámara de fotos (aprendió "leyendo manuales" y "equivocándose”), para hacer fotografías que él considera "artísticas". Retoca estas fotografías poniendo filtros con el programa Pickmonkey, para subirlas a redes sociales.

En casos como éste, "la herramienta se convierte en elemento configurador de las decisiones y resultados de (...) formas de producción juvenil de cultura visual" (AGUIRRE et al, 2015). Programas como Pickmonkey constituyen herramientas muy accesibles para los jóvenes, que nutren sus saberes técnicos e influyen sus producciones. En este sentido, "el propio medio se está convirtiendo en elemento impulsor de determinado tipos de prácticas (...) a través de la oferta de herramientas fáciles de manejar para la producción o manipulación de imágenes on line” (AGUIRRE I. ARRIAGA, A, MARCELLÁN, I. y CALVELHE, L., 2013).

\subsubsection{Saberes populares y religiosos}

Es Pablo el que se nutre principalmente de saberes populares y religiosos para sus producciones: el contexto en el que se mueve está tejiendo en él un imaginario concreto que se refleja cuando dibuja tronos de Semana Santa, Cristos y Vírgenes. Para hacerlo, echa mano de conocimientos muy específicos relacionados con la Semana Santa y 
con la imaginería religiosa: maneja vocabulario específico y conoce aspectos propios de este ámbito como sus pasos, sus hermandades o sus imágenes sagradas.

Junto a estos conocimientos, hemos detectado en Pablo un gusto estético característico de este contexto religioso y que condiciona su imaginario visual: cuando dibuja imágenes le interesa, especialmente, captar el parecido y la expresión de la cara. Le interesa que estas imágenes "emocionen". De hecho, cuando dibuja rostros, siempre sigue el mismo ritual: empieza dibujando los ojos, le preocupa captar la expresión del rostro (Figura 2).

Siente gusto, también, por las vestimentas adornadas de estas figuras, y por las ornamentaciones de su trono. A veces las sitúa en escenarios concretos, inspirados en momentos procesionales que reconoce como bellos o emotivos. Estos referentes enriquecen su sentido de pertenencia a un grupo concreto -el de las personas que se conmueven con estas imágenes-, y a un lugar concreto -Granada, su ciudad-.

Pablo suele ir, además, a ver exposiciones de hermandades que muestran imágenes y enseres de Semana Santa. Asiste a triduos, a besamanos, y visita iglesias para fotografiar imágenes y utilizarlas para sus dibujos.

Figura 2

Dibujos realizados por Pablo.

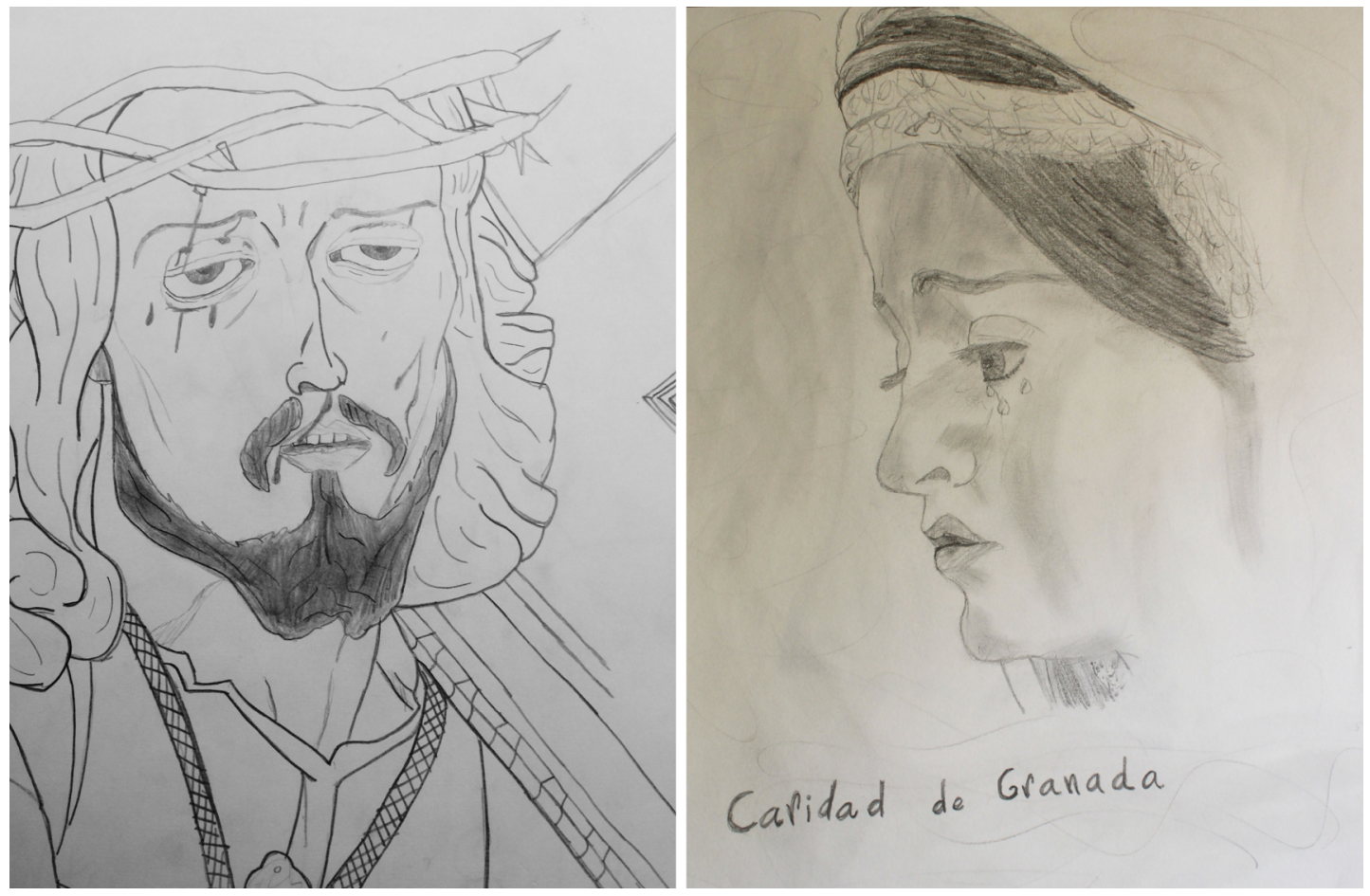

Fuente: propia. 
Pablo (P): Ayer fui a ver una exposición (...) de la Virgen de la Merced (...) y tienen ahí sus enseres de la hermandad (...). Aproveché que estaba abierta la iglesia de los Escolapios, entré y le hice fotos a la Virgen del Mayor Dolor, y una de las fotos es la que quiero dibujar.

El caso de Pablo resulta muy extraordinario, nada común entre los jóvenes. De hecho, tan sólo 5 de los 786 encuestados señalan la religión como uno de los temas que más les interesan a la hora de producir cultura visual, y 16 dicen usarlo con frecuencia, frente a 438 que dicen no usarlo nunca y a 243 que ni siquiera se han molestado en elegir la opción nunca.

En la entrevista, Pablo contaba que también había hecho, en menor medida, otros dibujos en los que se reflejan aspectos populares de su contexto cultural: por ejemplo, cuando llegaba la Feria del Corpus de Granada, empezó a dibujar mujeres vestidas de gitana. La estética que ofrecen estos referentes (mujeres con trajes de volantes, mantones, peinados con flores, poses y actitudes típicas de baile) forma parte de su imaginario popular y cultural y condiciona sus creaciones.

\subsubsection{Saberes extraídos de la Red}

En las entrevistas, tanto Ana como Pablo mencionan que utilizan Internet como una de las fuentes principales de donde extraen el material para abordar sus producciones. En este proceso están poniendo en juego un "saber digital", relacionado no solamente con la habilidad de utilizar un ordenador, sino, y sobre todo, con la habilidad para encontrar, ordenar, comprender, analizar y valorar información utilizando la tecnología digital.

Este "saber digital" les permite, como se verá a continuación, barajar información vinculada con la adquisición de conocimientos, habilidades y técnicas propias de los saberes descritos en los apartados anteriores, así como con la búsqueda y adquisición de referentes que utilizan para sus trabajos.

\section{a) Búsqueda de imágenes en Google}

Pablo comenta que utiliza con frecuencia el servicio de búsqueda de imágenes de Google para encontrar fotografías que quiere copiar: 


\author{
Entrevistadora (E): ¿Y de dónde sacabas las gitanas? \\ P: De internet. Yo me lo busco todo en internet, todas las fotos. \\ E: ¿Pero en blogs o en dónde? \\ P: En Google Imágenes y todo eso.
}

Uno de los usos más elementales de Internet entre los jóvenes creadores es el de tomar la red como un inmenso repositorio de imaginarios a partir del cual emprender y enriquecer su actividad creadora, hecho que ha sido validado por los datos de las encuestas: más del 70\% de los jóvenes preguntados nos han respondido que obtienen de Internet las imágenes que usan en sus producciones, frente al 26\% que recurren a material impreso y sólo un 13\% que las obtienen del material escolar. De manera que Internet se convierte, a los ojos de los jóvenes, como a los de muchos adultos, en la gran biblioteca o iconoteca donde recoger aquello que más les motiva y les inspira (AGUIRRE et al., 2015).

\title{
b) Uso de Facebook, Tuenti y Smartphones
}

Ambos entrevistados comentan que también utilizan Facebook y Tuenti como medios para obtener conocimientos que pueden enriquecer sus producciones. Este proceso a menudo pasa por el uso de su teléfono móvil. Por ejemplo, Pablo sabe utilizar su Smartphone para compartir en las redes sociales las fotografías que hace con el móvil y para buscar información o imágenes que necesita.

El habitual uso de esta herramienta tecnológica entre los jóvenes propicia la emergencia de una cultura de la interacción social informal muy fluida que repercute en su papel como productores. Pablo maneja este saber tecnológico, para mirar, entre otras cosas, el Tuenti de Sonia, novia de su hermano, que está haciendo Bachillerato Artístico, y consultar los dibujos a sombras que cuelga. También revisa el Facebook de su prima:

P: Mi prima, que está haciendo un curso de fotografía (...) siempre que tiene que elegir las fotos pues nos llama y nos dice que cuál es la que nos gusta más... Ella tiene Facebook, y pone casi todas las fotos allí... yo veo su Facebook. 
El hábil uso de esta herramienta permite a Pablo nutrir sus conocimientos técnicos y ampliar sus referentes. Como vemos, el uso de estas redes resulta determinante para el intercambio de papeles entre productores y usuarios de cultura visual (AGUIR$\mathrm{RE}, 2011)$. Este es un fenómeno ante el que las industrias culturales y publicitarias no permanecen ajenas, introduciendo publicidad contextual. Este ámbito constituye otro espacio que Pablo utiliza para enriquecer sus referentes y conectar con personas con las que comparte sus aficiones:

E: ¿Y conoces tú gente que también dibuje así, con lápiz (...)?

P: Bueno, yo tengo el Facebook de uno que se llama Jesús Mochón (...) Tiene un montón de dibujos de Semana Santa (...).

E: ¿Y cómo lo conociste?

P: No, no es que lo conociera... es que en Facebook, como tengo muchas cosas de Semana Santa, aparecen fotos suyas de sus dibujos y todo eso, y lo vi y dije ilo voy a agregar...! y lo agregué.

\section{c) Uso de Youtube, Foros y Páginas Web}

Pablo utiliza también Youtube para ver procesiones. Esta herramienta le sirvió como recurso, por ejemplo, para ver a la Virgen Macarena de Sevilla, que nunca ha visto, y poder dibujarla. A través de Youtube también encontró el "Foro la Recogía", un foro de Semana Santa al que es aficionado, gracias al que ha conocido una revista digital de carácter religioso en la que le han publicado un dibujo.

En el caso de Ana, es su madre la que suele consultar foros sobre punto de cruz para intercambiar y extraer patrones que Ana utiliza para sus producciones. Lo que Ana sí suele consultar son páginas web relacionadas con temas y técnicas que le interesan: a veces los contenidos de una página web la llevan a otra, y mediante esta búsqueda "en rizoma" va encontrando lo que le interesa.

E: (En relación a los "cupcakes" que hizo de fieltro) ¿Y de dónde sacas las ideas? A: Pues la verdad es que esto fue un día que estaba buscando diseños para mi madre, porque a mi madre le pintaba yo las uñas (...). Y buscando esos diseños me salió una página que te venía una bandejita y una tarta (...) y dije: imira qué monada, pues vamos a hacerlo! 
La madre de Ana también consulta páginas sobre hadas que le gustan a Ana, y le descarga imágenes que encuentra:

E: ¿Y esto Ana, cómo lo has hecho?

A: Pues es que me gustan las hadas, mucho. Y es lo mismo... mi madre me busca patrones, de punto de cruz, y yo lo saco... de los diseños que me gustan.

Como hemos indicado, Pablo y Ana utilizan el saber digital que les ofrece su interacción con la red para nutrir otros saberes específicos de los que beben para sus procesos creativos y, a la vez, reconocen su uso para encontrar el abanico de referencias que nutre sus creaciones. Google, Facebook, Tuenti, Youtube y diversos foros se configuran como los espacios por excelencia a los que acudir para obtener conocimientos y referentes. Este dato, sin embargo, se contrasta con el obtenido en los cuestionarios, donde los jóvenes explican que el origen de sus imágenes está siempre o frecuentemente en su imaginación (76\%), frente a un $5 \%$ que indica que en ningún caso recurre a su inventiva. Estos resultados rebaten la creencia generalizada, que también se presenta en este estudio de caso, de que los jóvenes extraen sus referentes de los medios de comunicación y especialmente de Internet, ya que según las respuestas este último sólo ofrece imágenes (siempre o con frecuencia) al 32\% de los encuestados, mientras que la televisión, los videojuegos o la publicidad lo hacen en el 12, 13 y 11\% de los casos respectivamente (AGUIRRE et al., 2013).

\subsection{Sobre el valor formativo que los jóvenes otorgan a los saberes no escolares}

En cualquier caso, hemos podido comprobar que Ana y Pablo no tienen, de entrada, una conciencia clara del abanico de saberes que ponen en juego cuando producen, no tienen sistematizado este proceso; esto es así, al menos, hasta que se les propone reflexionar sobre ello. Este dato parece ser generalizable. De hecho, con el análisis de los cuestionarios hemos podido comprobar que además de que los jóvenes no son conscientes de los saberes que pueden encerrarse en la actividad que realizan, tampoco los consideran necesarios o importantes. Así el 67\% de los encuestados señalaron estar 


\section{Figura 3}

Fotografía hecha por Pablo utilizando el programa PicMonkey.

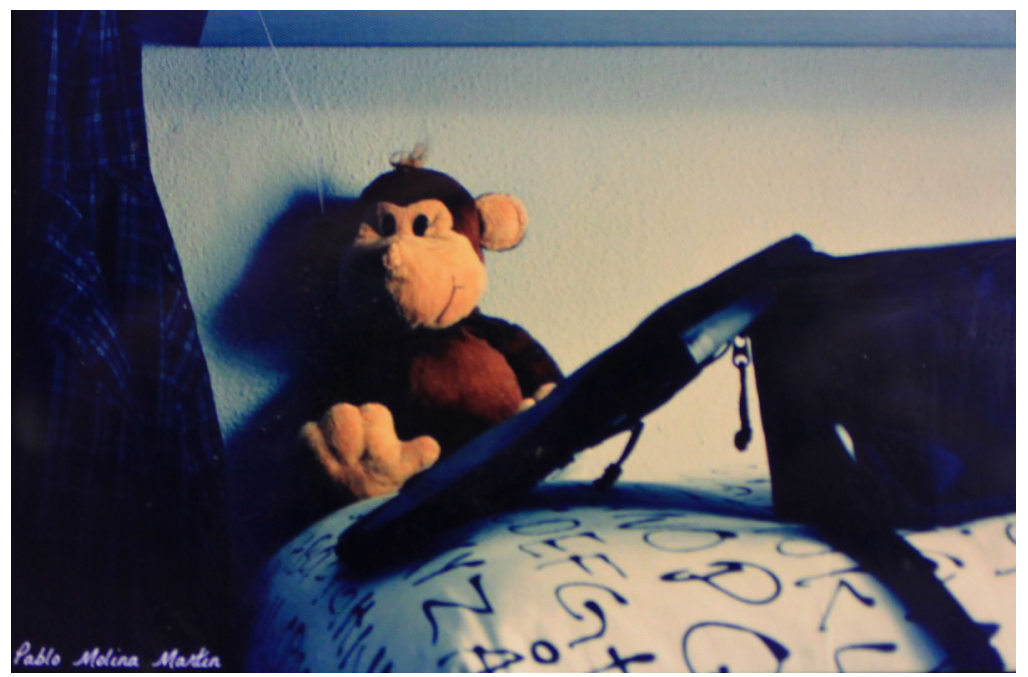

Fuente: propia.

totalmente o bastante de acuerdo con la idea de que para practicar su actividad es más importante tener medios que recibir enseñanzas.

A pesar de ello, hemos identificado un caso en el que Pablo reflexiona conscientemente sobre cómo determinados saberes tecnológicos le ayudan a enriquecer sus saberes artísticos. Lo indica refiriéndose al juego Art Academy de Nintendo:

\section{E: ¿Y estáis trabajando con las sombras en el instituto?}

P: No, en el instituto no. Pero yo tengo para la Nintendo DS... tengo Art Academy. Es un juego que te enseña a dibujar. A ver si te enseño... que había que hacer un pimiento (...) iy lo probé en la vida real para ver cómo me salía! En Art Academy te enseñaban así cómo eran las sombras, a combinar los colores.

También muestra esta conciencia cuando explica que hace "fotos artísticas", refiriéndose a fotografías que hace manejando su cámara réflex y que retoca con el programa PicMonkey (Figura 3).

E: ¿Y a ésta le has puesto hasta el nombre y todo, Pablo?

P: Sí, esa es que está retocada, porque le puse un filtro de luz, un marco (...) con un programa de internet que se llama PicMonkey (...). Hay diferentes filtros 
que hacen diferentes cosas (...). Lo que hago es que le pongo el sepia, y lo que quiero resaltar de color, pues le pongo el color a lo que quiero.

Pablo valora este saber tecnológico por los beneficios estéticos que reporta en sus imágenes y porque le ayuda a llevar a cabo su intencionalidad. Toma conciencia de estar utilizando la imagen como producto y siente que puede convertirse en autor, llegando a introducir su firma en las fotografías que interviene de esta forma.

\subsection{Sobre la repercusión del saber escolar en la construcción de los jó- venes como productores de cultura visual}

Los relatos presentados nos hacen ver el papel relevante que están jugando los entornos no escolares en las producciones personales de estos jóvenes, pero en la investigación también se pretendía observar y detectar de qué manera está repercutiendo el saber escolar en su construcción como productores de cultura visual. Por ello en las entrevistas les pedimos que nos enseñaran y comentaran sus trabajos escolares deteniéndose en los que más les interesaban y en los que menos, y explicando sus motivos.

Analizando tanto las imágenes como sus comentarios observamos que los aspectos de interés que destacan de sus trabajos escolares son, de un lado, aspectos estéticos que han aprendido a valorar en la escuela: que se parezca al original, que esté bien entonado, bien iluminado, detallado, limpio y bien acabado. De otro, aspectos de tipo técnico, que a su vez han utilizado para valorar sus producciones personales. Podemos observar ejemplos en el caso de Ana, relacionando el trabajo de texturas que hizo en $2^{\mathbf{o}}$ de ESO con el cuadro de "La Sabana" que hizo posteriormente en su casa, o relacionando el trabajo que hizo sobre sombras con puntillismo en $2^{\circ}$ de ESO con el "Dibujo de Rosa" que seguidamente hizo a título personal (Figuras 4 y 5).

A: (Refiriéndose al trabajo escolar sobre texturas) Esto lo hice en la ESO. iMira las texturas y todo...!

A: (Refiriéndose al cuadro de La Sabana) Con el pincel, lo mojé un poco, lo espachurré, y le empecé a dar así. Estilo así... icomo los arbolitos esos de la sabana! La textura de los árboles es lo que más me gusta. 
A: iÉste! (Refiriéndose al trabajo escolar sobre puntillismo) iAquí fue cuando yo vi eso de los puntitos! (...).

E: ¿Y crees que te ha ayudado?

A: Pues sí, la verdad es que eso me ayudó. iSi no llega a ser por los puntitos esos es que esto (refiriéndose al Dibujo de Rosa) a lo mejor ni lo hago!

\section{Figura 4}

A la izquierda trabajo sobre texturas de Ana, $2^{\circ}$ de ESO. A la derecha óleo sobre

"La Sabana", hecho por Ana fuera de la escuela.
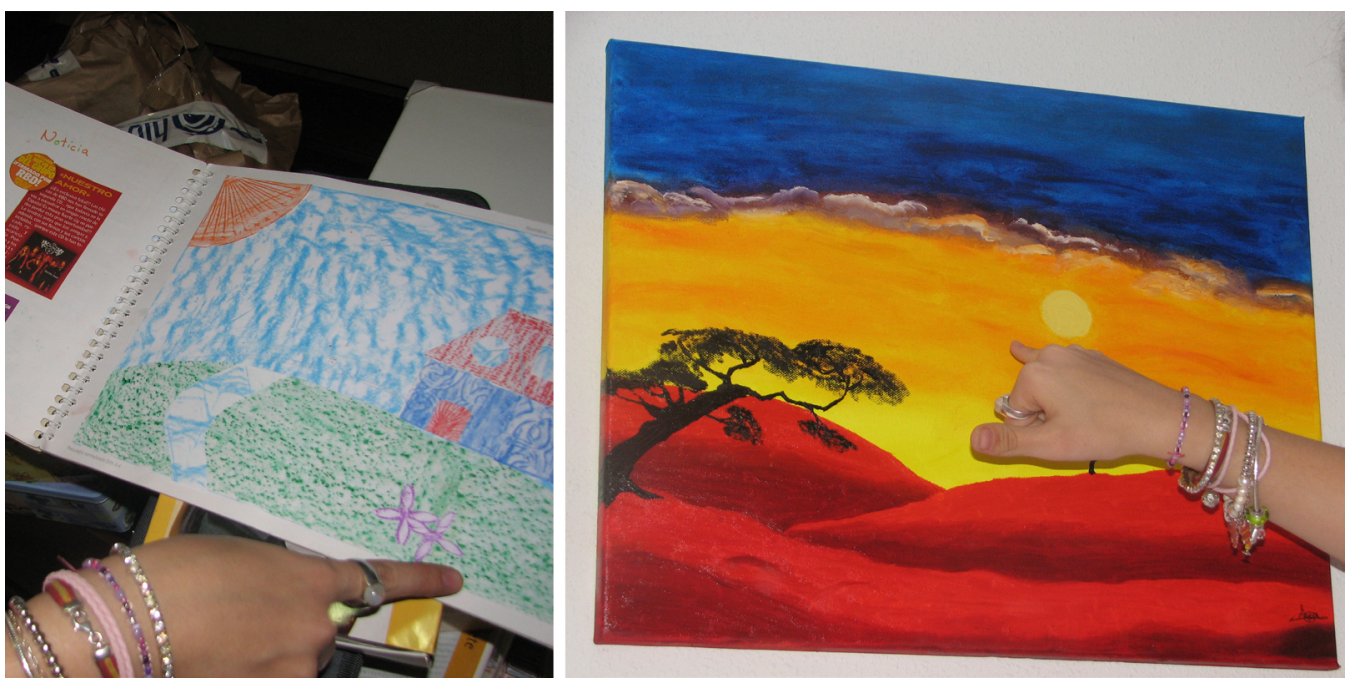

Fuente: propia.

\section{Figura 5}

A la izquierda trabajo sobre puntillismo de Ana, $2^{\circ}$ de ESO.

A la derecha "Dibujo de Rosa", hecho por Ana fuera de la escuela.
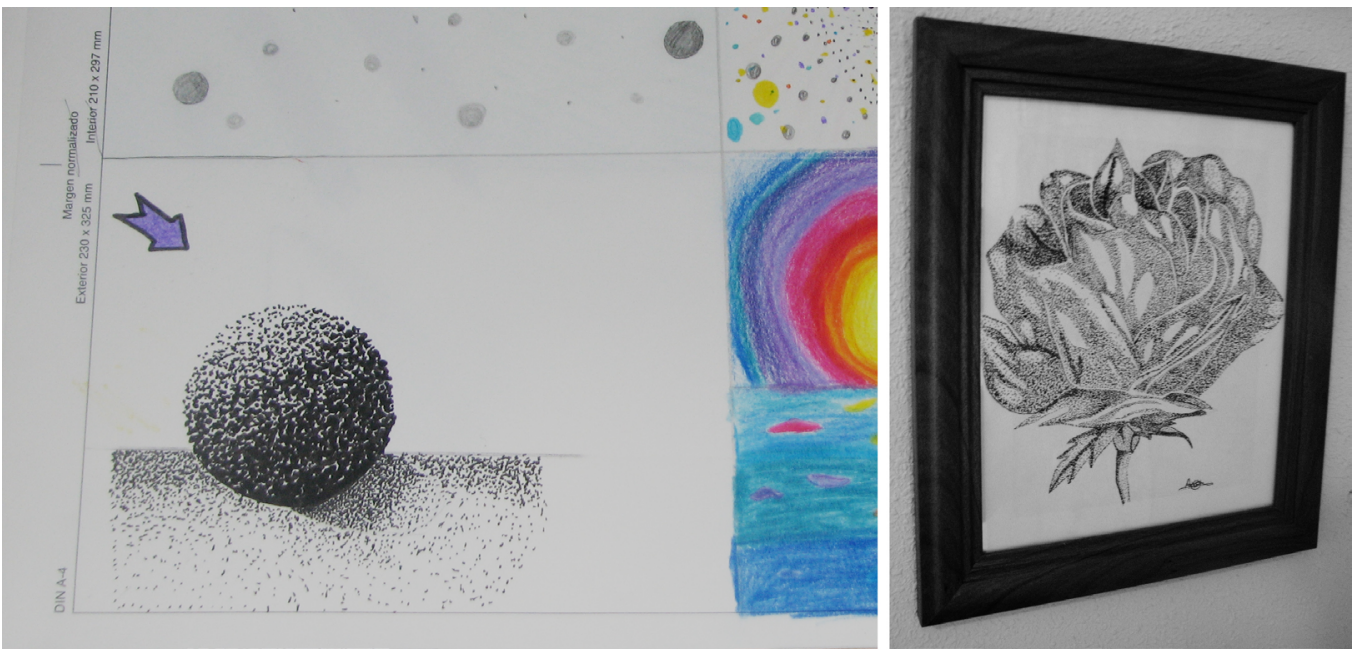

Fuente: propia. 
Por su parte, Pablo reconoce haber aprendido en el colegio alguna técnica que aplica en sus dibujos: "Yo en primaria tenía un profesor (...) me dijo una técnica que era hacer rayas... así... para que hacer una sombra no muy oscura pocas rayas, si es muy oscura pues muchas rayas así...”. Pero sobre todo se define como "autodidacta" en lo que a aprendizaje del dibujo se refiere: "Yo he aprendido por mi cuenta. Dibujando mucho cuando me aburría. Practicando mucho".

No obstante, los dos entrevistados son bastante críticos con el tipo de formación que reciben en el aula escolar. En sus relatos, se puede observar un distanciamiento entre lo que producen en ese espacio formal y lo que a ellos, realmente, les interesa crear.

P: ¿Las clases? Dibujo técnico, dibujo técnico... casi todo era dibujo técnico... de hacer líneas, líneas y más líneas. Ya mílo que me gustaba era hacer más cosas. Además, a veces le decía: "iProfesora, mándanos lo que queramos hacer!" y ella decía "no".

A: Es que... ieso no es Dibujo Artístico...! (...)Yo iba, eso, con una intención de aprender un montón de cosas, diciendo: "voy a aprender a sombrear con carboncillo, con tiza incluso, con témperas o con óleo...” y te llevas una desilusión de primera.

Este distanciamiento impide que Ana se relacione de forma personal con lo que hace en clase y que establezca una separación en su imaginario entre lo que considera "lo suyo" y "lo que no es suyo", es decir, lo que es materia escolar (I. AGUIRRE, comunicación personal, 5 de noviembre, 2010). Como ella misma explica, esta separación de intereses le llevó a "independizarse” de la escuela y hacer sus propias producciones.

A: iEn segundo yo ya empecé a independizarme! (risas) (...). Yo buscaba que me enseñaran cosas así curiosas, de manualidades(...) y como no me enseñaron cosas... pues entonces yo dije ipues me pongo a hacer lo mío!

Pablo argumenta, en un sentido similar, que sus intereses no coinciden con lo que se le pide en clase, lo que le llevaba a no esforzarse en la clase de Plástica. 
P: La nota máxima era un $10 . .$. yo sacaba $7,8,9 \ldots$ pero nunca he sacado un 10. Porque además es que... (refiriéndose a la profesora) era lo que ella quería hacer... iPues a mí no me interesaba mucho! (...) Y por eso no me esmeraba mucho.

Abordado de esta manera, el trabajo en la clase de Educación Plástica se constituye como algo ajeno a sus vidas. En este sentido, resulta curioso observar que cuando los trabajos de Plástica se vinculan con sus intereses, los recuerdan de forma muy significativa:

P: Yo tengo muchas ganas de poder dibujar del natural. Una vez hice un dibujo de los patios y de los árboles del colegio porque el profe de plástica de $1^{\circ}$ nos sacó a dibujar, iy me encantó!

Los casos de Pablo y Ana corroboran los resultados obtenidos del análisis de los cuestionarios. En ellos los jóvenes afirman que la escuela no ofrece ninguna o poca ayuda y sólo reconocen cierto "aprovechamiento" de los saberes escolares para su actividad productora cuando se trata del aprendizaje de técnicas, donde el 50\% sigue considerando que la escuela no ofrece ninguna o muy escasa ayuda, mientras un $27 \%$ considera que ayuda mucho o bastante (AGUIRRE, et al., 2013).

En general, los resultados obtenidos con los cuestionarios muestran que, para los jóvenes, la escuela no contribuye nada o casi nada a mejorar su producción visual, independientemente del tipo de práctica productiva sobre la que hayan ofrecido sus respuestas. Así, apenas reconocen la incidencia del profesorado y la escuela en la generación de cuestiones de interés para sus creaciones, en la adquisición de saberes para desarrollarlas o en la resolución de los problemas que se les pueden presentar en su actividad productiva (AGUIRRE et al., 2013).

Por último, varios relatos extraídos de las entrevistas revelan que la escuela no está teniendo en cuenta que estos jóvenes ya poseen algunos de los saberes que en ella se trabajan. Pablo, por ejemplo, ya tenía nociones sobre perspectiva y había hecho dibujos en los que la ponía en juego antes de trabajar este tema en el aula. 


\section{Figura 6}

Dibujo realizado por Pablo.

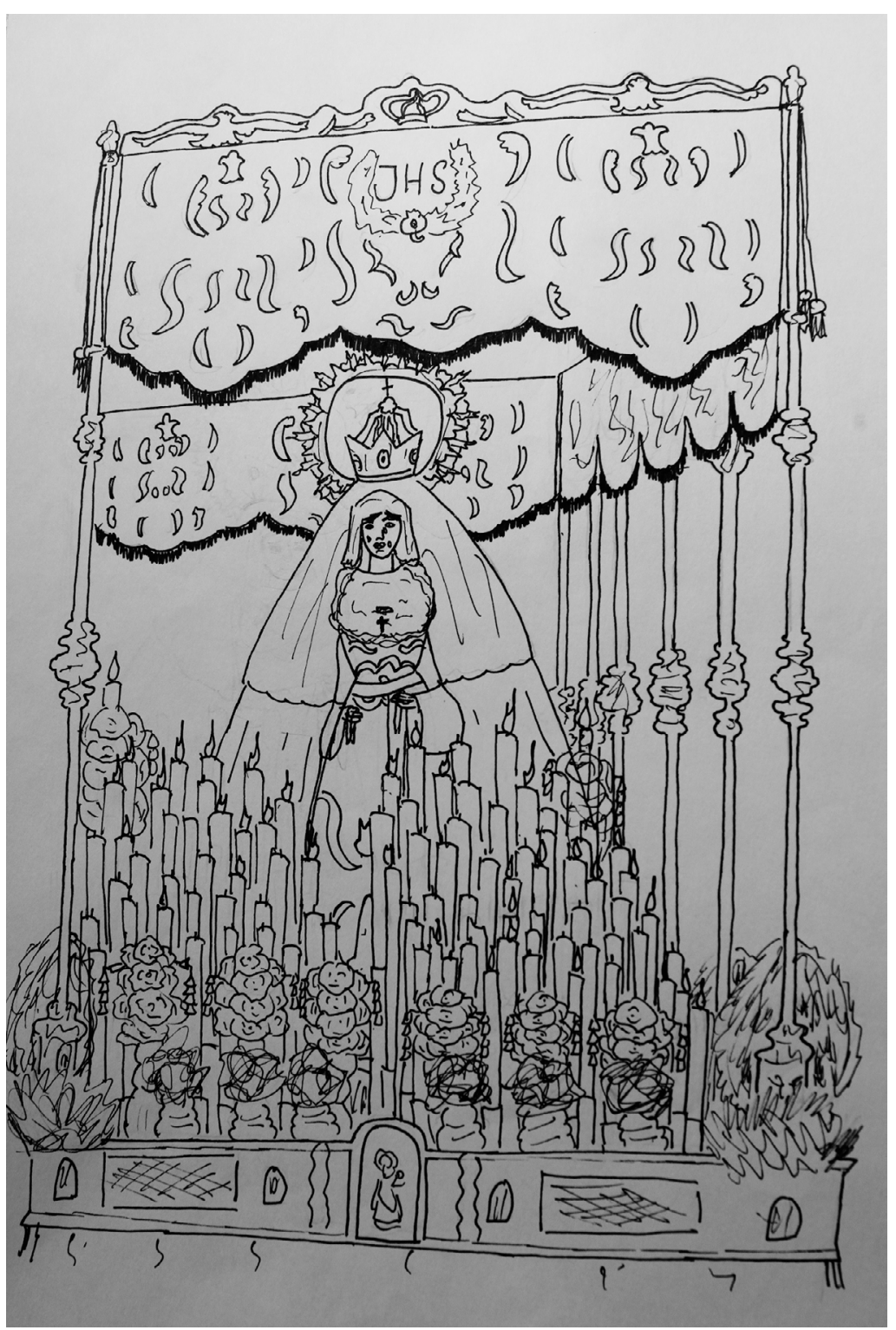

Fuente: propia.

E: ¿Y la perspectiva sí la estudiasteis en clase?

P: La perspectiva sí.

E: (En referencia a la Figura 6) ¿Y eso te ha servido para hacer esto, Pablo?

P: (Negación y risas) Pues en realidad no, porque yo cuando dibujaba esto no estábamos dando todavía eso... yo más bien... yo sabía ya prácticamente cómo era la perspectiva. 
Por otro lado, resulta curioso constatar que otras áreas de conocimiento escolar diferentes a Educación Plástica y Visual son las que proveen espacios para el aprendizaje relacionados con sus producciones personales; situaciones que hemos identificado en los dos casos expuestos. Pablo mencionaba, por ejemplo, que algunos de sus dibujos de Semana Santa los había hecho en clase de Religión, y que su profesor de Religión de primaria le enseñó a sombrear con líneas, técnica que aplicaba en sus dibujos personales. Mencionaba también que en su estancia de intercambio en Londres, su profesora de inglés le recomendó visitar un grafitti que era muy representativo de la ciudad de Brighton, y había hecho fotos de eso. Por su parte, Ana, hablando de su gusto por las cosas de papelería, destacó un tampón y un libro de caligrafía medieval a los que tenía especial cariño, y que había utilizado para hacer un trabajo en la asignatura de Francés.

\section{Conclusiones}

\subsection{Sobre los saberes no escolares que les influyen}

Una de las conclusiones remarcables en este estudio ha sido que, en un primer momento, tanto los jóvenes encuestados como los entrevistados han mostrado cierta falta de conciencia sobre los saberes que nutren sus producciones. Sin embargo, en las conversaciones mantenidas con ellos, han ido emergiendo una serie de fuentes y saberes que ponen en juego en sus producciones y que provienen, principalmente, de entornos no escolares.

Por ejemplo, hemos visto cómo saberes artesanales, populares y, en el caso de Pablo especialmente, los religiosos, son fundamentales en las producciones de los jóvenes de este estudio de caso. Así mismo, en sus relatos se ha visto el importante papel que juegan las nuevas tecnologías. Por un lado, la presencia de las TIC en su contexto cotidiano propicia unas lógicas de uso que están reconfigurando sus formas de acceder a la información -como el tipo de búsqueda "en rizoma" que Ana describe en referencia a internet-, influyendo en la forma de apropiación y de significación del conocimiento que precisan para abordar sus producciones. Por el otro, la tecnología de motores de búsqueda como Google les ofrecen un servicio que les estimula a asumir un mayor grado de autonomía y control sobre su propio aprendizaje (BUCKINGHAM, 2003), y les ofrece referencias que alimentan su lado creativo. Eso sí, de esta forma, 
hay que reseñar que es la lógica mercantil la que, en ausencia de las instituciones educativas, termina ofreciendo formación y modelos a las producciones de los jóvenes (MARCELLÁN, AGUIRRE, CALVELHE Y ARRIAGA, 2013).

Veíamos también que Pablo, como otros jóvenes productores, recurre a las redes sociales para desarrollar su voz e identidad como creador mediante la interacción con sus iguales y con las audiencias (BUCKINGHAM, 2008; ITO et al., 2008, 2012). El uso de estas redes, además, resulta determinante para el intercambio de papeles entre productores y usuarios de cultura visual (AGUIRRE, 2011).

Por tanto, si bien los jóvenes parecen no tener una conciencia clara respecto a los saberes que les acompañan en su producción, los comentarios de Ana y de Pablo nos han ayudado a detectar y corroborar ciertos valores referidos al entorno de los medios digitales que los nutre como productores y que merece la pena subrayar:

Los nuevos dispositivos (como el smartphone) y los sitios donde consultan o comparten las producciones (Tuenti, Facebook, YouTube, forums, etc.) están abriendo vías a Pablo y a Ana para crear y compartir contenidos (LANGE e ITO, 2008). En palabras de Imanol Aguirre, estos dispositivos "están favoreciendo una especie de nuevo entorno ecológico en el que se retroalimenta la aportación diaria de contenidos y su distribución entre los jóvenes implicados en la producción creativa”(2011, p.306).

Por otra parte, la producción que comparten en el entorno de los medios digitales les está permitiendo estrechar lazos entre sus iguales y generando comunidades (BUCKINGHAM, 2003) en las que (re) construyen e intercambian saberes (cuestiones de orden estético, técnico y formal) y sentidos (en relación a la construcción de su subjetividad). Estos nuevos entornos les está ofreciendo unas posibilidades creativas y democráticas importantes: ya no tienen que hacer lo que sus profesores ni sus padres decidan (BUCKINGHAN, 2000; ITO et al., 2008).

Así, podemos decir con Haanstra (2010) que el aprendizaje en los entornos no escolares se realiza de manera informal pero implica un aprendizaje intencional: ellos elijen lo que hacer y cómo hacerlo, según sus deseos y según lo que consideran importante.

A nuestro juicio tomar conciencia de la existencia de este tipo de saberes permite observar sus producciones más allá de su condición como objeto. Nos permite descentrar la mirada reconociendo que actúan como espejo de lo que estos jóvenes son, de cuáles son sus referentes, cómo construye su gusto, y de nosotros mismos al mirarlos (AGUIRRE, 2011). 


\subsection{Sobre la escuela como proveedora de saberes}

En sus relatos, Ana y Pablo reconocen que en la escuela han adquirido especialmente saberes de tipo técnico pero explican también que se da un distanciamiento entre lo que producen en ese entorno y sus propios intereses.

Sin embargo, ambos han aprendido a valorar lo artístico atendiendo a categorías estéticas que se fomentan en la escuela, como la semejanza con el referente y su correcta entonación y claroscuro, el detallismo o la limpieza. Posiblemente por esta razón, tanto Ana como Pablo no valoran como artísticas las creaciones personales que hacen en las que no encuentran estas cualidades. Una conclusión a la que también llega Mason (2005) que señala que las actividades de tipo manual (craft-based arts) son consideradas por los jóvenes "menores” en la jerarquía de las actividades de artes visuales.

Por otra parte, no reconocen la importancia de otras categorías del orden de lo emotivo, lo moral o lo afectivo con las que describen sus producciones personales.

En última instancia los relatos de Ana y Pablo y los resultados obtenidos en los cuestionarios están corroborando la hipótesis inicial de la investigación: la distancia entre cómo los jóvenes se relacionan con los saberes artísticos dentro y fuera de la escuela. Como hemos comentado en el apartado de resultados, la escuela no está teniendo en cuenta que estos jóvenes ya poseen algunos de los saberes que ponen en juego en sus creaciones, y otras áreas de conocimiento escolares son las que proveen espacios de aprendizaje relacionados con sus producciones personales.

Las reflexiones anteriores nos animan a reexaminar el papel que ocupa la escuela en la adquisición de los saberes artísticos. En este sentido, sin pretender que lo que decimos en esta investigación sea considerado un retrato de lo que son los jóvenes - lo que decimos es, más bien, lo que hemos visto que ocurre en aquello que hemos observado de estos jóvenes-, sí pensamos que pueden abrir ámbitos de análisis y de conocimiento.

\subsection{Coda final}

Por último nos queda reseñar que esta investigación nos ha permitido reflexionar sobre nuestra posición como investigadores. A este respecto podemos señalar varias cuestiones: 
Nos ha ayudado a silenciar nuestros prejuicios sobre lo que considerábamos “espacios de aprendizaje de saberes artísticos”. Al comienzo de nuestra investigación no imaginábamos, por ejemplo, que un chico de 14 años pudiera manejar los referentes religiosos que maneja Pablo para sus creaciones, ni que una chica de 16 tuviera un bagaje técnico tan profundo referido a las manualidades. Este estudio nos ha ayudado a atravesar nuestras propias representaciones de la adolescencia, a cuestionar nuestra mirada, y a tomar conciencia de la importancia que la contingencia tiene en estudios de este tipo.

Nos ha mostrado la importancia de explorar otras maneras de investigar el aprendizaje artístico de los jóvenes, desde la perspectiva de los saberes que contienen sus producciones y los referentes imaginarios a los que se vinculan.

Nos ha mostrado la necesidad de concebir a los jóvenes como productores de cultura visual y no sólo como meros consumidores. Esto supone un cambio de mentalidad importante: reconocerlos como autores y darles voz -solo se le da voz a quien se piensa que la tiene- (MARCELLÁN et al, 2013). Este trabajo ha subrayando la importancia que tiene la presencia de sus voces en este sentido, y nos ha iniciado en el camino que tomarán próximas exploraciones de este proyecto, considerándolos como coautores en las investigaciones.

\section{Referencias}

AGUIRRE, Imanol. Reflexividade e Desafios na Pesquisa com Jovens Produtores de Cultura Visual. En: MARTINS, Raimundo y TOURINHO, Irene (Orgs.). Processos e Práticas de Pesquisa em Cultura Visual e Educação. Santa Maria: Editora da UFSM, 2011.

AGUIRRE, Imanol. Los entornos del aprendizaje entre los jóvenes productores de cultura visual: rasgos y características. En MARTINS, Raimundo y TOURINHO, Irene (Orgs.). Pedagogias Culturais. Santa Maria (RS): Editora da Universidade Federal de Santa Maria, 2014.

AGUIRRE, Imanol (coord.). + $q$ knsmidrs d imgns: Mapeando evaluando la investigación sobre jóvenes productores de cultura visual. Pamplona: Pamiela-Edarte, 2015. 
AGUIRRE, Imanol; ARRIAGA, Amaia; MARCELLÁN, Idoia y CALVELHE, Lander. ¿Jóven*s productores de cultura visual? Reflexiones en torno a los resultados de un cuestionario. En EDARTE (Ed.). Investigar con jóvenes: ¿Qué sabemos de los jóvenes como productores de cultura visual? Pamplona: Pamiela- Edarte, 2013, p. 190-203.

AGUIRRE, Imanol; ARRIAGA, Amaia; GONZÁLEZ, M. Reyes; MARCELLÁN, Idoia; CALVELHE, Lander y OLÁIZ, Ilargui. Saberes y espacios de interacción de los jóvenes productores de cultura visual. En AGUIRRE, Imanol (coord.). + q knsmidrs d imgns: Mapeando y evaluando la investigación sobre jóvenes productores de cultura visual. Pamplona: Pamiela-Edarte, 2015, p. 45-62.

BUCKINGHAM, David. After the death of childhood. Growing up in the age of Electronic Media. Cambridge: Polity Press/Blackwell Publishing, 2000.

BUCKINGHAM, David. Media Education. Literacy, Learning and Contemporary Culture. Cambridge/Oxford: Polity Press/Blackwell Publishing, 2003.

BUCKINGHAM, David. (Ed.). Youth, Identity, and Digital Media. Massachussets: The MIT Press, 2008.

FREEDMAN, Kerry; HEIJNEN, Emiel; KALLIO-TAVIN, Mira; KÁRPÁTI, Andrea y PAPP, László. Visual Culture Learning Communities: How and What Students Come to Know in Informal Art Groups. Studies in Art Education. Número 54, vol.2, p. 103-115, 2013.

HAANSTRA, Folkert. Self-Initiated Art Work and School Art. International Journal of Art and Design Education, número 29, vol. 3, p. 272-281, 2010.

ITO, Mizuko; BAUMER, Sonja; BITTANTI, Matteo; BOYD, Danah; CODY, Rachel; HERR-STEPHENSON, Becky; et al. (Eds.). Hanging Out, Messing Around, Geeking Out: Living and Learning with New Media. Cambridge, MA: MIT Press, 2008.

ITO, Mizuko. Vivir y aprender con los nuevos medios: Resumen de las conclusiones del proyecto Digital Youth. En VVAA, La educación expandida. Sevilla: Zemos98, 2012. 
KÁRPÁTI, Andrea y KOVACS, Zita. Teenager art: Creating the self. Journal of Art and Design Education. Número 16, vol. 3, p.295-302, 1997.

LANGE, Patricia e ITO, Mizuko. Creative Production. En ITO, Mizuko; BAUMER, Sonja; BITTANTI Matteo; BOYD Danah; CODY Rachel; HERR-STEPHENSON Becky et al. (Eds.). Hanging Out, Messing Around, Geeking Out: Living and Learning with New Media. Cambridge, MA: MIT Press, 2008, p. 243-285.

LEANDER, Kevin y FRANK, Amy. The Aesthetic Production and Distribution of Image/Subjects among Online Youth. E-Learning. Número 3, vol.2, p. 185-206, 2006.

MANIFOLD, Marjorie. Cohee. What art educators can learn from the fan-based artmaking of adolescents and young adults. Studies in Art Education. Número 50, vol. 3, p. 257-271, 2009.

MARCELLÁN, Idoia y AGIRRE, Imanol. El valor educativo de los medios. Comunicar. Revista Científica Iberoamericana de Comunicación y Educación. Número 31, vol. XVI, p. 529-535, 2008.

MARCELLÁN BARACE, Idoia; CALVELHE, Lander; AGUIRRE, Imanol y ARRIAGA, Amaia. Estudio sobre jóvenes productores de cultura visual: evidencias de la brecha entre la escuela y la juventud. Arte, Individuo y Sociedad. Número 25, vol. 3, p. 524-534, 2013.

MASON, Rachel. The meaning and value of home-based craft. International Journal of Art \&Design Education. Número 24, vol. 3, p. 261-8, 2005.

STERN, Susannah. Adolescent girl's expression on web home pages: Spirited, sombre and self-conscious sites. Convergence: The journal of Research into New Media Technologies. Número 5, vol. 4, p. 22-41, 1999.

Recibido el: 01/03/2018

Aceptado en: 07/10/2019

Publicado en: 13/05/2020 